\title{
Western equine encephalitis
}

INSERM

\section{Source}

INSERM. (1999). Orphanet: an online rare disease and orphan drug data base. Western equine encephalitis. ORPHA:83593

Western equine encephalitis (WEE) is an acute arboviral infection caused by an alphavirus of the Togaviridae family transmitted by an infected mosquito, that more frequently affects children and that is characterized by the presence of mild flulike symptoms (fever, chills, headache, nausea, vomiting, and anorexia) but that can prog ress to weakness, altered mental status, photophobia, mental confusion, seizures, somnolence, coma and/or even death. The disease can leave neurological sequelae, mainly in infants and children, such as seizures, spasticity or behavioral disorders. 